УДК 620.22:621.763-037.47

Буря О. I. ${ }^{1}$, Томіна А.-М. В. ${ }^{1}$, Теренін В. I. ${ }^{2}$, Губарєв I. В. ${ }^{1}$

${ }^{1}$ Дніпровський державний технічний університет. Україна, м. Кам'янське

${ }^{2}$ Всеросійський науково-дослідний інститут полімерних волокон. РФ, м. Митищі

\title{
ВПЛИВ ТЕРМОСТІЙКОГО ВОЛОКНА ЛОЛА НА ВЛАСТИВОСТІ ОРГАНОПЛАСТИКІВ НА ОСНОВІ ФЕНІЛОНУ С-1
}

В статті розглядається як випливає волокно із гетероциклічного поліарилену сходової будови лола, на фізико-механічні властивості ароматичного поліаміду фенілону С-1. За результатами випробувань встановлено, що армування вихідного полімеру волокном з гетероциклічного поліарилену сходової будови підвищує: модуль пружності, межу плинності та твердість на 7-15, 13-15 та 13-15\% відповідно, що дозволить застосовувати розроблений матеріал в машинобудуванні, хімічній, текстильній та інших галузях промисловості. [dx.doi.org/10.29010/082.6]

Ключові слова: фенілон C-1; лола; органопластики; модуль пружності; межа плинності; органічне волокно. 


\section{Вступ}

В останні роки композиційні матеріали (КМ) на основі реакто- та термопластів армовані органічними волокнами (ОВ), володіючи великою твердістю, стійкістю до високих температур, впевнено зайняли одне з основних місць серед конструкційних (сталь, алюміній, бронза і т.п.) та спеціальних матеріалів, які не завжди відповідають потребам в сучасному ракето-, авіа-, автобудуванні та космічній техніці [1-3]. Чим більше розвиваються ці галузі, тим більше в них використовуються КМ, тим вище становиться якість цих матеріалів [4], шляхом підбору складу та властивостей наповнювача можна отримати матеріали з заданим поєднанням експлуатаційних і технологічних властивостей, таких як міцність, жорсткість, діапазон робочих температур [5]. Деталі з КМ знижують матеріалоємність в зв'язку з малою масою та значно більш високим коефіцієнтом корисного використання матеріалу. Інколи внаслідок високої вартості деяких пластмас зниження маси матеріалу на конструкцію не приводить до зменшенню затрат на метал, однак при виготовленні металевих деталей задіянні три види обробки з великою кількість операцій (до 30-50), а пластмасових деталей - тільки один - формування деталей [6].

На першому місці по ефективності (відношенню ціна-якість) стоять композиційні матеріали на основі термопластів [7], серед яких виділяють ароматичні поліаміди, що цікаві для практичного використання. Одним 3 перспективних наповнювачів для отримання надміцних та легких матеріалів являються OB, які несуть основне навантаження, що виникає в композиції при дії зовнішніх навантажень, та забезпечує жорсткість та міцність композиції [8]. Важливим фактором який визначає механічні властивості матеріалу армованого волокнами, являється зв'язок, який існує на границі поділу «в'яжуче-наповнювач». Визначення мікротвердості є одним з найбільш конструктивних сучасних методів дослідження даного зв'язку.

Враховуючи вище сказане, метою даної роботи являлось дослідження фізико-механічних характеристик органопластиків (ОП) на основі ароматичного поліаміду фенілону C-1, армованого волокном сходової будови лола.

\section{Об'єкти та методи досліджень}

В якості в'яжучого використовували ароматичний поліамід фенілон С-1 (ТУ 6-05-221-101-71) тонкодисперсний порошок рожевого кольору 3 насипною густиною $0,2-0,3$ г $/ \mathrm{cm}^{3}$, що характеризується наступними властивостями: густина -

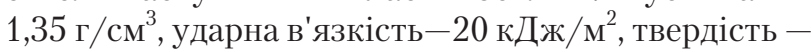

180 МПа, температура розм'якшення за Віка 543 К. Призначається для виготовлення пластмасових виробів методом прямого пресування [9].

В якості наповнювача обрали волокно із гетероциклічного поліарилену сходової будови - лола табл. 1, що має виняткову вогне-, термо- та стійкість до дії концентрованих кислот та органічних розчинників, створеному у ВНДІВіВ (м. Митищі) на основі мономерів, отриманих Тульським ВНДІПО (ангідрид) та Новосибірським IOX СО АН СРСР (амін) [10].

Таблиця 1

\section{Властивості волокна лола}

\begin{tabular}{|l|c|}
\hline \multicolumn{1}{|c|}{ Показники } & Величина \\
\hline Густина, кг м $^{3}$ & $1400-1500$ \\
\hline Модуль пружності, ГПа & $30-45$ \\
\hline Міцність, сН/текс & $35-45$ \\
\hline Розривне подовження, \% & $3-6$ \\
\hline $\begin{array}{l}\text { Збереження міцності } \\
\text { - при 573 К; } \\
\text { - після нагріву при 573 К } \\
\text { (на протязі 100 год) }\end{array}$ & $\begin{array}{c}70-85 \\
80-9\end{array}$ \\
\hline Вологість (н.у.), \% & $2-3$ \\
\hline
\end{tabular}

Приготування композицій фенілону C-1 що містять 5-20 мас.\% [11] органічного волокна лола (15 мм), здійснювалося методом сухого змішування в апараті з обертальним електромагнітним полем (0,12 Тл) за допомогою феромагнітних частинок, які з приготовленої композиції вилучались методом магнітної сепарації.

Перед формуванням поліамід фенілон С-1 та композиції необхідно ретельно висушити. Переробка в вироби невисушених матеріалів погіршує їх показники міцності, що призводить до утворення поверхневих дефектів (раковин, пухирів і ін.). Сушка заготовок проводилася в термошафі SPT-200 протягом 2-3 годин при 473-523 К. Пігулка з термошафи відразу ж завантажувалася в прес-форму, нагріту до 523 К. Після завантаження в прес-форму матеріал нагрівали до 598 К і витримували без тиску 10 хвилин, після чого давали витримку в 10 хвилин при тиску 30 МПа і тій же температурі. Далі виріб охолоджували при постійному тиску до температури 543 К і проводили розпресування.

Дослідження структури розроблених органопластиків здійснювали на мікроскопі «Біолам-М». Густину зразків визначали адитивним та гідростатичним методом згідно ГОСТ 15139-69.

Особливості стиснення органопластиків вивчали на універсальній машині FP-100. Твердість та мікротвердість визначали відповідно за допомогою твердоміру 2074 ТПР та мікротвердоміру ПМТ - 3М. 
Коефіцієнт Пуассона (1), модуль зсуву (2), модуль об'ємного стиснення (3), параметр Ламе (4) розраховували за формулами:

$$
\begin{gathered}
\mu=\frac{\left(E-6 \cdot \sigma_{m}\right)}{\left(6 \cdot \sigma_{m}+2 \cdot E\right)}, \\
G=\frac{E}{2 \cdot(1+\mu)}, \\
K=\frac{E}{3 \cdot(1-2 \cdot \mu)}, \\
\lambda=\frac{\mu \cdot E}{(1+\mu) \cdot(1-2 \cdot \mu)},
\end{gathered}
$$

де $E$ - модуль пружності, МПа; $\sigma_{m}-$ межа плинності при стисненні, МПа.

\section{Результати досліджень}

Важливу інформацію, щодо пружних характеристик матеріалу, характеру та величину пластичної деформації, міцності та межі плинності дає дослід на стиснення. На рис.1 наведена залежність навантаження $(\sigma)-$ деформація $(\varepsilon)$. Криві $1,3-5$ (фенілон C-1 та органопластики на його основі, що місять 10-20 мас.\% волокна), згідно класифікації Херцберга [12] відносяться до кривих $V$ типу, який характеризує пружну гетерогенну - пластичну поведінку. На ділянці кривих до 170 МПа, спостерігається повністю пружна поведінка матеріалу, далі форма кривих являє собою результат конкурентного розвитку двох процесів. Перший процес характеризується пластичною течією, за рахунок руйнування вихідної структури полімеру, результатом чого звичайно являється падіння навантаження. Другий процес характеризується перебудовою

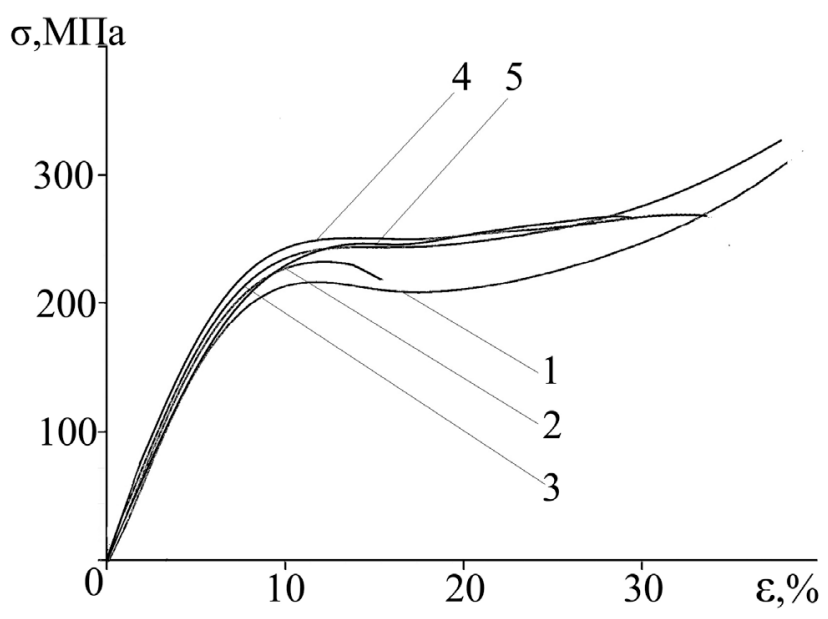

Рис. 1. Криві $\sigma-\varepsilon$ фенілона С-1 (1), та органопластиків, армованих 5 (2); 10 (3); 15 (4); 20 (5) мас. \% волокна

зруйнованої структури у нову, за рахунок накопичених деформаційних напружень.

ОП що містить 5 мас.\% волокна, відноситься до кривих II типу - що характеризує пружну гомогенну-пластичну поведінку. Окрім прямолінійної ділянки, що відповідає пружній деформації зразків, спостерігається параболічна ділянка кривої, що описує гомогенну пластичну деформацію, яка призводить до незворотніх змін форми. Пластична деформація виникає в результаті незворотного руху дислокацій, в результаті крива в своїй параболічній частині піднімається до деякого максимального значення, за рахунок зростаючого опору з сторони матеріалу нарощування пластичної деформації.

Виходячи з наведених даних табл. 2 даних видно, що наповнення вихідного матеріалу 5-15 мас.\% волокна, позитивно впливає на його міцністні характеристики: підвищує модуль пружності, межу плинності та твердість на $7-15,13-15$ та $13-15 \%$ відповідно, що можна пояснити достатньо великим контактом макромолекул в'яжучого з поверхнею наповнювача. При подальшому збільшенні кількості волокна до 20 мас.\%, спостерігається їх спад, що можна пояснити зростанням дефективності мате-

Таблиця 2

Фізико-механічні характеристики органопластиків

\begin{tabular}{|l|c|c|c|c|c|}
\hline \multirow{2}{*}{\multicolumn{1}{|c|}{ Показник }} & \multicolumn{5}{c|}{ Вміст волокна, мас.\% } \\
\cline { 2 - 6 } & - & $\mathbf{5}$ & $\mathbf{1 0}$ & $\mathbf{1 5}$ & $\mathbf{2 0}$ \\
\hline Модуль пружності, МПа & 2754 & 2945 & 3130 & 3246 & 2985 \\
\hline Межа текучості при стисненні, МПа & 206 & 0 & 237 & 242 & 240 \\
\hline Коефіцієнт Пуассона & 0,225 & - & 0,22 & 0,22 & 0,20 \\
\hline Модуль здвигу, G МПа & 1124 & 1472 & 1280 & 1342 & 1235 \\
\hline Модуль об'ємного стиснення, К МПа & 1670 & 981 & 1879 & 1973 & 1707 \\
\hline Параметр Ламе, $\lambda$ МПа & 920 & 0 & 1025 & 1090 & 883 \\
\hline Твердість НRЕ & 88 & 101 & 102,5 & 103 & 101 \\
\hline
\end{tabular}




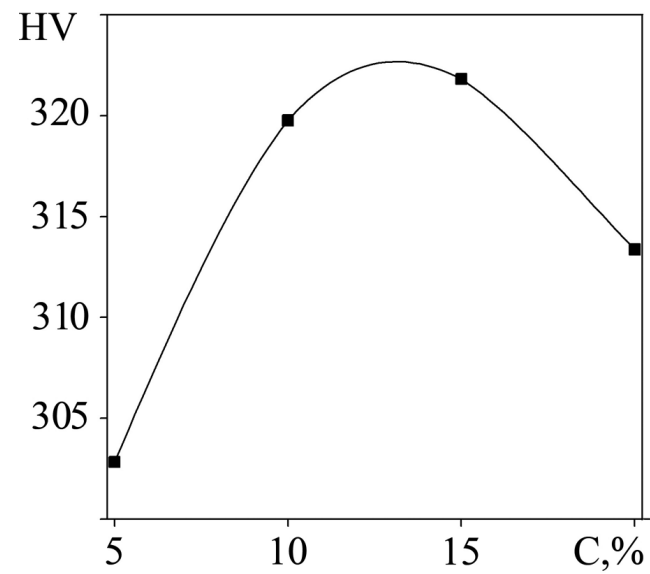

Рис. 2. Мікротвердість органопластиків на границі «в’яжуче-волокно»

ріалу - об’ємна доля в'яжучого не достатня для змочування волокна, внаслідок чого утворюються пори, що підтверджується значеннями мікротвердості на границі поділу «в'яжуче-волокно» рис. 2.

Підтвердженням сказаного служить той факт що густина ОП визначена гідростатичним методом вища ніж передбачувана адитивна при вмісті 515 мас.\% наповнювача, а в подальшому при 20 мас.\% нижча за передбачувану рис. 3.

\section{Висновок}

Аналіз результатів дослідження фізико-механічних властивостей органопластиків, свідчить що використання органічного волокна лола, для армування $є$ перспективним шляхом підвищення міцністних характеристик вихідного полімеру: підвищує модуль пружності та межу плинності на 7-15 та $13-15 \%$ відповідно.

\section{Література}

[1] Полимерные композиционные материалы в конструкциях летательных аппаратов Г.М. Гуняев, В.В. Кривонос, А.Ф. Румянцев [и др.] [Текст] // Конверсия в машиностроении. - 2004. - №4. - С. 65 - 69 .

[2] Рогов В.А. Классификация композиционных материалов и их роль в современном машиностроении / В.А. Рогов, М.И. Шкарупа, А.К. Велис [Текст] // Вестник РУДН. - 2012. - №2. - С. 41 - 49.

[3] Евгений Каблов. Композиты: сегодня и завтра [Текст] /Евгений Каблов// Наука и технологии. 2015. - C. $36-39$

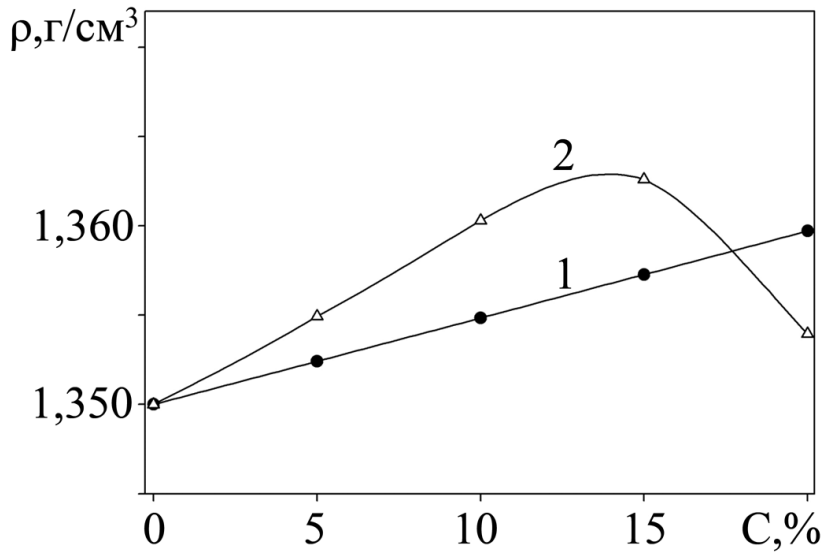

Рис. 3. Розрахункова (1) та експериментальна (2) густина вихідного полімеру та органопластиків на його основі

[4] Ал. Ал. Берлин. Современные полимерные композиционные материалы [Текст] /Ал. Ал. Берлин// Соросовский Образовательный Журнал. - 1995. №1. - С. $57-65$.

[5] Неразрушающий контроль качества композиционных материалов [Текст] / В.А. Троицкий, М.Н. Карманов, Н.В. Троицкая // Техническая диагностика и неразрушающий контроль. - 2014. - № 3. - С. $29-33$.

[6] Гурченко П.С. Композиционные и неметалические материалы в машиностроении: учеб.-метод. пособие [для студентов инженерно-технических специальностей] [Текст] / П.С. Гурченко, В.Г. Дашкевич. Минск: БНТУ, 2012. - 407 с.

[7] П.Ю. Мажирин Полифениленсульфид в авиастроении [Текст] / П.Ю. Мажирин // Материалы. 2003. - C. $22-24$.

[8] Сафин В.Н. Композиционные материалы [Текст] / Сафин В.Н. - Челябинск, ЮУрГУ, 2010. - 36 с.

[9] Технология производства химических волокон [Текст] / [Ряузов А.Н., Груздев В.А., Бакшеев И.П. и др.]; [учебник для техникумов. $-3-$ е изд. перераб. и доп.] - М.: Химия, $1980-448$ с.

[10] Информация Всероссийский научно-исследовательский институт полимерных волокон [Текст] // Хим.волокна. 1975.- №3. - С. 36-37.

[11] Пат. № 105957 України, МПК F16C 19/00. Термостійка композиція [Текст] / Буря O.I., Набережна О.О., Томіна А.-М.В., Теренін В.І. - № u 2015 10084; заяв. 15.10.2015.; опубл. 11.04.2016. Бюл. № 7.

[12] Херцберг Р. В. Деформация и механика разрушения конструкционных материалов [Текст] / Р. В. Херцберг. пер. с англ. // под. ред. М.Л. Бернштейна. - М.: Металлургия. $-1989 .-560$ с. 
Burya A. I. ${ }^{1}$, Tomina A.-M. V. ${ }^{1}$, Terenin V. I. ${ }^{2}$, Gubarev I. V. ${ }^{1}$

${ }^{1}$ Dneprovskii State Technical University. Ukraine, Kamenskoe

${ }^{2}$ All-Russian Research Institute of Polymer Fibers. Russia, Mytishchi

\section{INFLUENCE OF THERMAL FIBER LOLA ON THE PROPERTIES OF ORGANOPLASTICS BASED ON PHENYLONE C-1}

The paper considers how the fibers from the heterocyclic polyarylene of the staircase structure, lola, and the physical and mechanical properties of the aromatic polyamide of phenylone $C$-1 appear. According to the results of the tests it was established that the reinforcement of the initial polymer with fiber from the heterocyclic polyarylene of the ladder structure increases: the modulus of elasticity, flow margin and hardness at 7-15, 13-15 and 13-15\% respectively, which will allow the application of the developed material in mechanical engineering, chemical, textile and other industries. [dx.doi.org/10.29010/082.6]

Keywords: phenylone C-1; Lola; organoplasty; elastic modulus; elasticity limit; organic fiber.

\section{References}

[1] Polymer composite materials in aircraft structures G.M. Gunyaev, V.V. Krivonos, A.F. Rumyantsev [and etc] [Text] // Conversion in engineering. -2004 . - №4. - P. $65-69$.

[2] Rogov V.A. Classification of composite materials and their role in modern engineering / V.A. Rogov, M.I. Shkarupa, A.K. Velis [Text] // Newsletter PFUR. - 2012. - №2. - P. 41 - 49.

[3] Evgeny Kablov. Composites: today and tomorrow [Text] /Evgeny Kablov// Science and technology. - 2015. P. $36-39$.

[4] Al. Al. Berlin. Modern polymer composite materials [Text] /Al. Al. Berlin// Soros Educational Journa. - 1995. - №1. P. $57-65$.

[5] Non-destructive quality control of composite materials [Text] / V.A. Troitsky, M.N. Karmanov, N.V. Troitskaya // Technical diagnostics and non-destructive testing.-2014. - № 3. - P. $29-33$.

[6] Gurchenko P.S. Composite and non-metallic materials in engineering: teaching method. allowance [for students of engineering and technical specialties] [Text] / P.S. Gurchenko, V.G. Dashkevich. - Minsk: BNTU, 2012. - 407 p.

[7] P.Yu. Mazhirin Polyphenylene sulfide in the aircraft industry [Text] / P.Yu. Mazhirin // Materials. - 2003. -P. $22-24$.

[8] Safin V.N. Composite materials [Text] / Safin V.N. - Chelyabinsk, SUSU, 2010. - 36 p.

[9] Technology of production of chemical fibers [Text] / [Ryauzov AN, Gruzdev VA, Baksheev I.P. and etc.]; [textbook for technical schools. - 3rd ed. Pererab. and additional.] - M.: Chemistry, $1980-448$ p.

[10] Information All-Russian Scientific Research Institute of Polymer Fibers [Text] // Chemical fibers. 1975.- №3. P. 36-37.

[11] Pat. № 105957 Ukraine, MPK F16C 19/00. Heat-resistant composition [Text] / Burya A.I., Naberezhnaya O.O., Tomina A.-M.V., Terenin V.I. - № u 2015 10084; stat. 15.10.2015.; post. 11.04.2016. Bullet. № 7.

[12] Herzberg R.V. Deformation and mechanics of structural materials destruction [Text] / P.B. Herzberg. trans. from english // under the editorship M.L. Bernstein. - M.: Metallurgy . - 1989. - 560 p. 